\title{
Current ventilation practice during general anaesthesia: a prospective audit in Melbourne, Australia
}

\author{
Dharshi Karalapillai ${ }^{1,2^{*}}$, Laurence Weinberg ${ }^{2}$, Jonathan Galtieri ${ }^{3}$, Neil Glassford ${ }^{1}$, Glenn Eastwood ${ }^{1}$, Jai Darvall ${ }^{3}$, \\ Jake Geertsema ${ }^{4}$, Ravi Bangia ${ }^{5}$, Jane Fitzgerald ${ }^{6}$, Tuong Phan ${ }^{7}$, Luke OHallaran ${ }^{8}$, Adriano Cocciante ${ }^{9}$, \\ Stuart Watson ${ }^{9}$, David Story ${ }^{10}$ and Rinaldo Bellomo ${ }^{11,12}$
}

\begin{abstract}
Background: Recent evidence suggests that the use of low tidal volume ventilation with the application of positive end-expiratory pressure (PEEP) may benefit patients at risk of respiratory complications during general anaesthesia. However current Australian practice in this area is unknown.

Methods: To describe current practice of intraoperative ventilation with regard to tidal volume and application of PEEP, we performed a multicentre audit in patients undergoing general anaesthesia across eight teaching hospitals in Melbourne, Australia.

Results: We obtained information including demographic characteristics, type of surgery, tidal volume and the use of PEEP in a consecutive cohort of 272 patients. The median age was 56 (IQR 42-69) years; 150 (55\%) were male. Most common diagnostic groups were general surgery (31\%), orthopaedic surgery (20\%) and neurosurgery (9.6\%). Mean $\mathrm{FiO}_{2}$ was 0.6 (IQR 0.5-0.7). Median tidal volume was $500 \mathrm{ml}$ (IQR 450-550). PEEP was used in 54\% of patients with a median value of $5.0 \mathrm{cmH}_{2} \mathrm{O}(\mathrm{IQR}$ 4.0-5.0) and median tidal volume corrected for predicted body weight was $9.5 \mathrm{ml} / \mathrm{kg}$ (IQR 8.5-10.4). Median peak inspiratory pressure was $18 \mathrm{cmH}_{2} \mathrm{O}$ (IQR 15-22). In a cohort of patients considered at risk for respiratory complications, the median tidal volume was still $9.8 \mathrm{ml} / \mathrm{kg}$ (IQR 8.6-10.7) and PEEP was applied in $66 \%$ of patients with a median value of $5 \mathrm{cmH}_{2} \mathrm{O}$ (IQR 4-5). On multivariate analyses positive predictors of tidal volume size included male sex $(p<0.01)$, height $(p=0.04)$ and weight $(p<0.001)$. Positive predictors of the use of PEEP included surgery in a tertiary hospital ( $\mathrm{OR}=3.11 ; 95 \% \mathrm{Cl}: 1.05$ to 9.23$)$ and expected prolonged duration of surgery ( $\mathrm{OR}=2.47 ; 95 \% \mathrm{Cl}: 1.04$ to 5.84$)$.
\end{abstract}

Conclusion: In mechanically ventilated patients under general anaesthesia, tidal volume was high and PEEP was applied to the majority of patients, but at modest levels. The findings of our study suggest that the control groups of previous randomized controlled trials do not closely reflect the practice of mechanical ventilation in Australia.

Keywords: Tidal volume, PEEP, Intraoperative ventilation, Anaesthesia

\section{Background}

It is estimated that 783,000 patients undergo general anaesthesia per year in Victoria, Australia [1]. In this setting, mechanical ventilation is often mandatory to support respiratory function. Despite its necessity, mechanical ventilation has many potentially detrimental effects

\footnotetext{
* Correspondence: dharshi.karalapillai@austin.org.au

${ }^{1}$ Department of Intensive Care, Austin Hospital, Melbourne, Australia

${ }^{2}$ Department of Anaesthesia, Austin Hospital, Melbourne, Australia

Full list of author information is available at the end of the article
}

on lung tissue. In the context of critical care medicine, ventilator induced lung injury can result from cyclic overstretching of aerated alveoli with high tidal volume ventilation, from repeated opening and closing of peripheral airways, from low lung volume associated with recruitment and de-recruitment of unstable lung units, and from the application of high airway pressures [2,3]. Whether short exposure to potentially injurious mechanical ventilation in patients with healthy lungs is sufficient to initiate lung damage is a subject of controversy.
C Biomed Central 
Currently the optimal management of intraoperative mechanical ventilation is not known. In particular, uncertainty exists with regard to the optimal tidal volume and the need for and the optimal value of positive end expiratory pressure (PEEP).

Randomized trials support the use of a low tidal volume strategy and the application of PEEP in critically ill patients with acute lung injury or acute respiratory distress syndrome (ARDS), who require prolonged mechanical ventilation $[4,5]$. These findings suggest that it may be physiologically logical and desirable to apply a similar ventilation strategy to other patient groups such as patients undergoing intra-operative ventilation under general anaesthesia. A recent randomized controlled trial of patients at risk of respiratory complications undergoing major abdominal surgery showed that a low tidal volume strategy and the application of PEEP had clinical advantages over standard care [6]. In the standard care group of this study, the average tidal volume of $>11 \mathrm{ml} / \mathrm{kg}$ and PEEP was not used. Furthermore, recently a large multi centre trial in a similar cohort of patients compared a low PEEP versus high PEEP strategy when combined with a tidal volume of $8 \mathrm{ml} / \mathrm{kg}$ found no significant difference in the incidence of respiratory complications [7]. The relevance and external validity of these findings in other health care systems remains unclear, as there is no understanding or knowledge of current practice in other developed countries such as Australia. We hypothesized that anaesthetists in Australia would adopt a "conventional strategy" of high tidal volume (i.e. $10-12 \mathrm{ml} / \mathrm{kg}$ ) with the application of PEEP. Accordingly, we conducted a prospective multicentre audit to define current practice of intra-operative mechanical ventilation in the city of Melbourne, Australia.

\section{Methods}

With ethics approval (HREC/14/Austin/260) and in accordance with the STROBE guidelines for observational studies, we conducted a multicentre audit across eight teaching hospitals in Melbourne, Australia [8]. These included: The Austin Hospital, The Royal Melbourne Hospital, The Northern Hospital, St Vincents Hospital, The Alfred Hospital, Monash Medical Centre, The Western Hospital and Box Hill Hospital. Five of these hospitals were tertiary referral hospitals with individual centres being statewide referral centres for liver transplant, spinal injury, trauma, and cardiac and lung transplantation. One tertiary centre and all secondary centres included obstetric services. We collected data on all adults (greater than 18 years) patients undergoing surgery at two distinct time points (10 h00 and $14 \mathrm{~h} 00)$, on three consecutive days $(28 / 8 / 2013$ to $30 / 8 / 2013)$. At these designated times, an observer entered the operating room and obtained information regarding demographic characteristics, patient co-morbidities, type and predicted length of surgery and details of intra-operative ventilation including the patient-ventilator interface used, inspired oxygen concentration, ventilation mode, tidal volume, respiratory rate, use and amount of PEEP applied, and peak inspiratory pressures. Treating anaesthetists were blinded to the purpose of the study. Predicted body weight was calculated as $50+2.3$ [height $(\mathrm{cm}) /(2.54-60)]$ for men and $45.5+2.3$ [height $(\mathrm{cm}) /(2.54-60)$ ] for women [9].

We analysed the following subgroups i) patients who underwent general anaesthesia; ii) patients whose ventilator interface was an endotracheal tube; and iii) patients whose ventilator interface was an endotracheal tube and who were considered at increased risk of respiratory complications on the basis of age, type and duration of surgery, emergency surgery and the presence of comorbid respiratory disease or recent respiratory infection $[10,11]$. We excluded patients who underwent intracranial surgery from this high-risk group due to concerns about intracranial hypertension potentially influencing ventilator settings (i.e. a low tidal volume strategy may lead to hypoventilation, hypercapnia and increased intracranial pressure).

\section{Data handling and statistical analysis}

Data were incomplete for $16.5 \%(n=33)$ of outcomes. Outcomes of interest included use of PEEP (of any value) and tidal volume selected. Descriptive statistics were tabulated for all patients receiving general anaesthesia, by method of airway management, by hospital type, by individual site, and by high risk of respiratory complications. Univariate comparisons of means, medians or proportions, as appropriate, were performed. Factors thought to be clinically important in determining the application of PEEP were considered for multi-variable logistic regression analysis. Only patients undergoing general anaesthesia requiring endotracheal intubation and mechanical ventilation were considered. Model variables considered included: age, sex, ASA score, presence of significant respiratory disease, type of surgery (e.g. emergency, general, cardiothoracic, neurosurgery), prolonged duration of surgery ( $>2$ hours), type of hospital (secondary or tertiary centre), height and weight. To assess the robustness of the model, height and weight were replaced with body mass index, and predicted lean body weight. The area under the receiver operator characteristic curve (c-statistic, AuROC) and the Hosmer-Lemeshow (goodness-of-fit) test were used to assess model adequacy. Data are presented as odds ratios (OR) with 95\% confidence intervals (CI). A p-value $<0.05$ was considered statistically significant.

To identify independent predictors of intra-operative tidal volume in intubated patients undergoing general anaesthesia, backwards multiple linear regression analysis 
was performed using those factors thought to be clinically relevant as independent covariates: height, weight, age, ASA score, gender, presence of significant respiratory disease, type of surgery (emergency, cardiothoracic, major abdominal, neurosurgery), prolonged duration of surgery ( $>2$ hours), and type of hospital (secondary or tertiary centre). Data are presented as estimates with standard errors, and $\beta$ standardized coefficients. A p-value $<0.05$ was considered statistically significant. SPSS version 20 (IBM, North Castle, NY, USA) was used for all statistical analyses.

\section{Results}

\section{Demographics}

In a cohort of 272 consecutive patients from eight teaching hospitals in the city of Melbourne, Australia, the median age was 56 years (IQR 42-69) and 150 (55\%) patients were male. The most common types of surgery performed were general in $86(31.6 \%)$ patients, orthopaedic in $55(20.2 \%)$ patients and urological in $20(7.4 \%)$ patients. Overall, 26 (9.6\%) patients underwent intracranial neurosurgery. Patient characteristics are summarized in Table 1).

For the 262 patients undergoing general anaesthesia, an endotracheal tube was used in $200(76 \%)$ patients and a supraglottic airway device in $41(16 \%)$ patients with 17 (5\%) of patients receiving facemask anaesthesia. One patient $(0.4 \%)$ had a tracheostomy in situ and $1(0.4 \%)$ patient underwent rigid bronchoscopy. For the 200 patients with an endotracheal tube, volume control mode was used in $146(73 \%)$ patients, while $46(23 \%)$ patients received pressure control ventilation and only 2 patients received pressure support ventilation. Mean Fi02 was 0.6 (IQR 0.5-0.7) and median absolute tidal volume was $500 \mathrm{ml}$ (IQR 468571). Median tidal volume per predicted body weight was $9.7 \mathrm{ml} / \mathrm{kg}$ (IQR 8.6-10.5). PEEP was used in $132(66 \%) \mathrm{pa-}$ tients with a median value of $5 \mathrm{cmH}_{2} \mathrm{O}$ (IQR 4-5). Median maximum inspiratory pressure was $19 \mathrm{cmH}_{2} \mathrm{O}$ (IQR 16-22). Details of ventilation during anaesthesia are summarized in Table 2. For the 81 patients who were considered at increased risk of perioperative respiratory complications, the median tidal volume was $9.8 \mathrm{ml} / \mathrm{kg}$ (IQR 8.6-10.7) lean body mass and PEEP was applied in $68 \%$ of cases at a median level of $5 \mathrm{cmH}_{2} \mathrm{O}$ (IQR 4-5).

In tertiary hospitals the median tidal volume per predicted body weight was $9.7 \mathrm{ml} / \mathrm{kg}$ (IQR 8.9-10.8) and 120 of the $176(66.3 \%)$ patients received PEEP at a median value of 5 (IQR 4-5). Results were similar in secondary hospitals with a median tidal volume of $9.9 \mathrm{ml} / \mathrm{kg}$ (IQR 7.9-12.5) and 22 of 34 (64.7\%) patients had PEEP applied at a median value of $5 \mathrm{cmH} 20$ (IQR-5-5.25).

\section{Predictors of intra-operative PEEP use and tidal volume} On multi-variable logistic regression analysis, type of hospital (OR 3.11; 95\% CI: 1.05 to 9.23, p = 0.04) and
Table 1 Characteristics of study patients

\begin{tabular}{|c|c|}
\hline Age in years & $56(42-69)$ \\
\hline Male (\%) & $150(55)$ \\
\hline Height in $\mathrm{cm}$ & $170(162-176)$ \\
\hline Actual weight in $\mathrm{kg}$ & $75(67-89)$ \\
\hline Ideal body weight in kg & 52.9 (IQR 48.6-58.6) \\
\hline Body mass index in $\mathrm{kg}$ per $\mathrm{m}^{2}$ & 25.9 (IQR 24.4- 30.8) \\
\hline \multicolumn{2}{|l|}{ ASA status (\%) } \\
\hline । & $48(17.6)$ \\
\hline$\|$ & $107(39.4)$ \\
\hline III & $81(29.8)$ \\
\hline IV & 29 (10.6) \\
\hline V & $1(0.4)$ \\
\hline Unknown & $6(2.2)$ \\
\hline Emergency & $22(8.1)$ \\
\hline Respiratory disease (\%) & $73(26.8)$ \\
\hline Cardiac disease (\%) & $66(24.3)$ \\
\hline \multicolumn{2}{|l|}{ Type of surgery (\%) } \\
\hline General & $86(31.6)$ \\
\hline Cardiac & $21(7.7)$ \\
\hline Thoracic & $6(2.2)$ \\
\hline Maxillofacial/Dental & $9(3.3)$ \\
\hline Gynaecology & $2(0.7)$ \\
\hline Obstetrics & $4(1.4)$ \\
\hline Opthalmology & $4(1.5)$ \\
\hline Orthopaedics/Spinal & $55(20.2)$ \\
\hline Neurosurgery & $26(9.6)$ \\
\hline Urology & $20(7.4)$ \\
\hline Vascular & $15(5.5)$ \\
\hline Plastics/Burns & $16(6.1)$ \\
\hline Other & $8(3)$ \\
\hline \multicolumn{2}{|l|}{ Hospital type (\%) } \\
\hline Secondary & $48(17.6)$ \\
\hline Tertiary & $224(82.4)$ \\
\hline \multicolumn{2}{|l|}{ Type of anaesthesia (\%) } \\
\hline General anesthesia & $262(96.3)$ \\
\hline Regional anaesthesia & $10(3.7)$ \\
\hline \multicolumn{2}{|c|}{ Expected duration of surgery (\%) } \\
\hline$<30$ mins & $12(4.4)$ \\
\hline $30-60$ mins & $56(20.6)$ \\
\hline $1-2$ hrs & $82(30.1)$ \\
\hline $2-4 \mathrm{hrs}$ & $79(29.0)$ \\
\hline$>4 \mathrm{hrs}$ & $30(11.0)$ \\
\hline Unknown & $13(4.9)$ \\
\hline
\end{tabular}

Values are median (IQR) or number (percentage). 
Table 2 Details of ventilation during anaesthesia

\begin{tabular}{|c|c|c|c|c|}
\hline & All patients $\mathrm{N}=\mathbf{2 7 2}$ & GA N $=262$ & GAETT $=200$ & GA ETT High risk $\mathrm{N}=81$ \\
\hline Height (cm) & $170(162-176)$ & $170(162-176)$ & $170(162-175)$ & $170(162-175)$ \\
\hline Absolute weight (kg) & $75(67-89)$ & $75(67-88)$ & $78(67-90)$ & $79(65-89)$ \\
\hline Ideal body weight (kg) & $52.9(48.6-58.6)$ & $52.9(48.6-58.6)$ & $53.8(48.4-58.7)$ & $54.3(48.4-58.5)$ \\
\hline Body mass index $\left(\mathrm{kg} / \mathrm{m}^{2}\right)$ & $26(24.4-30.8)$ & $25.9(23.4-30.0)$ & $26.2(23.8-31.2)$ & $26.3(23.4-31.1)$ \\
\hline \multicolumn{5}{|l|}{ Patient-ventilator interface (\%) } \\
\hline ETT & $200(73.5)$ & $200(76.3)$ & $200(100)$ & $81(100)$ \\
\hline LMA & $41(15.1)$ & $41(15.6)$ & 0 & 0 \\
\hline Mask & $17(6.3)$ & $17(4.5)$ & 0 & 0 \\
\hline Tracheostomy & $1(0.4)$ & $1(0.4)$ & 0 & 0 \\
\hline Nil (including rigid bronchoscopy) & $11(4.1)$ & $1(0.4)$ & 0 & 0 \\
\hline Unknown & $2(0.7)$ & $2(0.8)$ & 0 & 0 \\
\hline $\mathrm{FiO}_{2}$ & $0.60(0.5-0.7)$ & $0.60(0.50-0.70)$ & $0.60(0.50-0.70)$ & $0.60(0.50-0.75)$ \\
\hline \multicolumn{5}{|l|}{ Ventilation mode (\%) } \\
\hline VCV & $148(54.4)$ & $148(48.9)$ & $146(73)$ & $59(72.8)$ \\
\hline PCV & $54(19.4)$ & $54(20.6)$ & $46(23)$ & $17(21)$ \\
\hline PSV & $10(3.7)$ & $10(3.8)$ & $2(1)$ & $2(2.5)$ \\
\hline SV & $47(17.3)$ & $37(14.1)$ & 0 & 0 \\
\hline Jet & $1(0.4)$ & $1(0.4)$ & 0 & 0 \\
\hline Unknown & $12(4.8)$ & $12(4.6)$ & $6(3)$ & $3(3.7)$ \\
\hline Absolute tidal volume (ml) & $500(450-550)$ & $500(450-550)$ & $500(468-471)$ & $500(475-578)$ \\
\hline Tidal Volume ( $\mathrm{ml} / \mathrm{kg}$ lean body mass) & $9.5(8.5-10.4)$ & $9.5(8.5-10.4)$ & $9.7(8.6-10.5)$ & $9.8(8.6-10.7)$ \\
\hline Respiratory Rate (b/minute) & $12(10-12)$ & $12(10-12)$ & $12(10-12)$ & $11(10-12)$ \\
\hline PEEP Yes (\%) & $146(53.7)$ & $146(55.7)$ & $132(66 \%)$ & $51(63)$ \\
\hline PEEP $\left(\mathrm{cmH}_{2} \mathbf{0}\right)$ & $5.0(4.0-5.0)$ & $5.0(4.0-5.0)$ & $5.0(4.0-5.0)$ & $5.0(4.0-5.0)$ \\
\hline Peak inspiratory pressure $\left(\mathrm{cmH}_{2} \mathrm{O}\right)$ & $18(15-22)$ & $18(15-22)$ & $19(16-22)$ & $19(16-22)$ \\
\hline
\end{tabular}

Values are median (IQR) or number (percentage); GA general anaesthesia, GAETT general anaesthesia with an endotracheal tube, GAETT high risk: general anaesthesia with an endotracheal tube with increased risk of respiratory complications, $\mathrm{FiO}_{2}$ inspired oxygen concentration, $E T T$ endotracheal tube, $L M A$ laryngeal mask airway, VCV volume control ventilation, PCV pressure control ventilation, PSV pressure support ventilation, SV spontaneous ventilation, $P E E P$ positive end-expiratory pressure.

prolonged surgery (OR 2.47; 95\% CI: 1.04 to $5.84, \mathrm{p}=0.04)$ were positive independent predictors of PEEP use, while cardiothoracic surgery and neurosurgery were negative independent predictors of the use of intraoperative PEEP (Table 3). These relationships remained

Table 3 Multi-variable logistic regression analysis for use of intra-operative PEEP in intubated patients undergoing general anaesthesia

\begin{tabular}{llll}
\hline Received PEEP & OR & $\mathbf{9 5 \% ~ C l}$ & p-value \\
\hline Tertiary centre & 3.11 & $1.05-9.23$ & 0.04 \\
Type of surgery & & & \\
Cardiothoracic & 0.19 & $0.05-0.70$ & 0.01 \\
Neurosurgery & 0.26 & $0.08-0.91$ & 0.04 \\
Prolonged surgery $(>2$ hours) & 2.47 & $1.04-5.84$ & 0.04 \\
\hline
\end{tabular}

AUC 0.76 (95\% Cl: 0.69 to 0.84); Hosmer-Lemeshow GoF, $p=0.84$. (OR Odds Ratio, Cl Confidence Interval). unchanged when BMI and predicted body weight were substituted for absolute weight and height in the model. Height, weight and male gender were positive predictors of higher tidal volume; ASA score was a negative predictor of higher tidal volume (Table 4).

\section{Discussion \\ Key findings}

We conducted a prospective audit in eight teaching hospitals in the city of Melbourne, Australia to determine current ventilation practice during anaesthesia. We found that, in mechanically ventilated patients under general anaesthesia, tidal volume was high (approximately $10 \mathrm{ml} / \mathrm{kg}$ predicted body weight) and that PEEP was applied to the majority of patients, but only at modest levels (approximately $5 \mathrm{cmH}_{2} \mathrm{O}$ ). In addition, we found that the type of hospital and prolonged surgery were both positive independent predictors of PEEP use, whilst cardiothoracic 
Table 4 Multiple linear regression analysis for use of intra-operative tidal volume in intubated patients undergoing general anaesthesia

\begin{tabular}{llllll}
\hline Variable & Estimates & Standard error & $\mathbf{9 5 \%} \mathbf{C l}$ & $\boldsymbol{\beta}$-co-efficient & $\mathbf{p}$-value \\
\hline Male & 49.17 & 12.66 & 24.16 to 74.17 & 0.29 & -0.16 \\
ASA score & -23.57 & 9.79 & -42.9 to -4.25 & 0.001 \\
Weight & 1.15 & 0.28 & 0.60 to 1.71 & 0.28 & $<0.001$ \\
Height & 1.38 & 0.67 & 0.06 to 2.7 & 0.16 & 0.04 \\
\hline
\end{tabular}

(95\% Cl: $95 \%$ confidence interval of the estimate; $\beta$-co-efficient: standardised estimate expressed as standard deviations).

surgery and neurosurgery were negative independent predictors for the use of PEEP. Significant predictors of higher tidal volume were gender, height, and weight. Furthermore, even in patients at high risk of respiratory complications, the average tidal volume was approximately $10 \mathrm{ml} / \mathrm{kg}$ lean body mass and there was no difference in the use of PEEP.

\section{Comparison with previous studies}

To our knowledge, this the first multicentre study evaluating intra-operative ventilation practices in Australian teaching hospitals. A recent retrospective analysis of over 200,000 patients from two institutions in the United States reported similar findings with a median tidal volume of around $9 \mathrm{ml} / \mathrm{kg}$ and PEEP use in approximately $60 \%$ at a median amount of $5 \mathrm{cmH}_{2} \mathrm{O}$ [12]. Our findings are also consistent with a subsequent retrospective study of over 29,000 patients from a single centre in the United States who reported a similar median tidal volume [13].

However, in a multicentre study of a mixed surgical population in France, the frequency of PEEP use was only 19\% [14]. Predictors of the use of PEEP in our study included surgery in a tertiary hospital and expected prolonged duration of surgery. The former suggests that the use of PEEP may be institution specific. Interestingly, increased weight did not predict the use of PEEP, a finding that contrasts with other studies [13]. Predictors of the absence of PEEP in our study included patients undergoing cardiothoracic surgery and neurosurgery. The omission of PEEP in patients undergoing neurosurgery is logically explained on the basis of a potential exacerbation of intracranial hypertension with PEEP. However its omission from cardiothoracic surgery is of interest given this group is considered at increased risk of perioperative respiratory complications [15]. One possible explanation for this relationship may be that many of our observations in cardiac surgery patients may have been taken when ventilation was suspended whilst patients were on cardiopulmonary bypass. It is a common practice for PEEP to be removed at this time to facilitate surgical access.

The median tidal volume in our study was $500 \mathrm{ml}$, which was also the most frequent tidal volume used (Figure 1). This may be explained by the default setting for tidal volume in volume control mode on many anaesthesia machine ventilators being $500 \mathrm{ml}$. In our study the positive predictors of increased tidal volume included male gender, height and weight. The association of the latter two with tidal volume is similar to published findings [14]. Male gender has been previously associated with lower tidal volumes [14]. However in our study a higher tidal volume was delivered to males, which was independent of their actual weight and height. This suggests that anaesthetists may have set tidal volumes with an assumption of a higher body weight in these patients, irrespective of their actual measured weight. One potential explanation of the high tidal volume approach to ventilation in our study may be that Australian anaesthetists calculated tidal volume according to absolute body weight rather than predicted body weight, even though predicted body weight has been used to calculate tidal volume in previous studies of intra-operative ventilation [4-6,10,16-19].

Despite the necessity and frequency of intra-operative mandatory ventilation, the optimal ventilator settings with regard to tidal volume and PEEP are not known. Previous recommendations have advocated a high tidal volume strategy of $10-12 \mathrm{ml} / \mathrm{kg}$ predicted body weight, citing reduced oxygen requirements and reduced incidence of atelectasis as potential benefits [20]. It appears

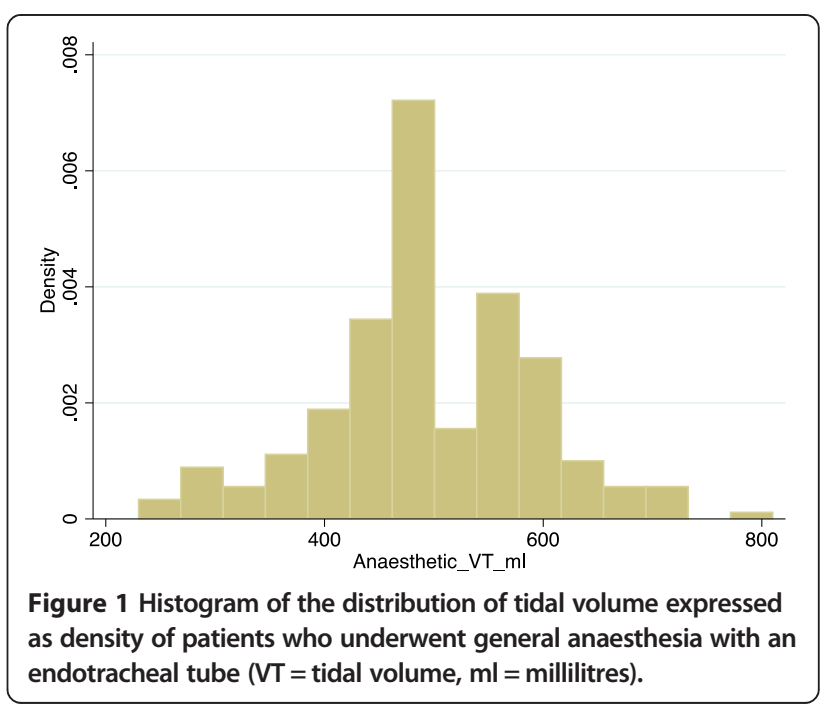


that our findings with respect to tidal volume are more consistent with a traditional approach $(10 \mathrm{ml} / \mathrm{kg})$ as opposed to a low tidal volume strategy $(6 \mathrm{ml} / \mathrm{kg})$.

The benefits of a low tidal volume strategy first became apparent in randomized controlled trials of critically ill patients with acute respiratory distress syndrome [19-21]. A lung protective strategy (low tidal volume and the application of PEEP) resulted in reduced mortality and is now considered standard of care in these patients. However, studies of a low tidal volume strategy in patients without lung injury when mechanically ventilated under anaesthesia have yielded inconsistent results $[10,15,22,23]$. On the one hand, low tidal volume strategies have been associated with reduced lung and systemic inflammatory responses [24-26] and reduced respiratory complications [27]. Moreover, experimental and clinical studies have suggested that mechanical ventilation using large tidal volumes could initiate lung injury in healthy lungs [10,28-34] especially during major surgery with its associated inflammatory response, which makes the lungs more vulnerable to mechanical ventilation induced injury [35-38]. On the other hand, many of these studies of low tidal volume have used small patient populations or have focused on different and not necessarily clinically relevant outcomes [23]. This has led to significant controversy in the literature with some authors suggesting that a low tidal volume strategy is unnecessary in patients without acute lung injury, citing the need for increased oxygen requirement, increased risk of auto-PEEP (due to high respiratory rates), hypercapnia and atelectasis [22] as potentially harmful effects [34]. In this regard, a retrospective analysis of over 29,000 patients suggested the use of low intraoperative tidal volume with minimal PEEP $(4 \mathrm{cmH} 20)$ is associated with an increased 30-day mortality when compared to a more conventional ventilation strategy with minimal PEEP [13]. The authors speculated that this might have been related to an increased atelectasis. Experimental evidence has linked this with increased bacterial growth and translocation and the development of lower respiratory tract infections [39,40].

Recently, in a multicenter randomized trial, Futier et al. investigated the effect of a low tidal volume strategy in patients undergoing major abdominal surgery who were considered at increased risk for perioperative respiratory complications [6]. Their findings suggested that a low tidal volume strategy with PEEP was associated with reduced need for postoperative ventilator assistance. However, the standard care group included a ventilation strategy with an average tidal volume in excess of $11 \mathrm{ml} / \mathrm{kg}$ and no PEEP [6]. Similarly in a study performed by Servegnini and colleagues in major abdominal surgery [27], a tidal volume of $7 \mathrm{ml} / \mathrm{kg}$ and PEEP $10 \mathrm{cmH}_{2} \mathrm{O}$ in conjunction with recruitment manoeuvres was associated with improved postoperative pulmonary function tests, gas exchange, chest $x$-ray findings and reduced pulmonary infections when compared to a standard care group who received a tidal volume of $9 \mathrm{ml} / \mathrm{kg}$ and no PEEP or recruitment manoeuvres. However the absence of PEEP in the standard care arm of both of these studies is not consistent with the Australian cohort of this study. Previous evidence suggests that application of PEEP in itself may be lung protective independent of tidal volumes. PEEP may prevent atelectasis [41], micro-aspiration [42], and decrease the need for rescue therapies for hypoxia [19]. Low or absent PEEP may increase shear stress and lung injury independent of the absence of high plateau pressures due to the cyclic collapse and tidal recruitment of lung units referred to as "atelectatrauma" [43]. Previous work suggests that the combination of a large tidal volume without PEEP may itself induce injury in healthy lungs in proportion to the duration of ventilation and promote pulmonary complications [24].

A recent multicenter study by the PROVE Network investigators directly compared the effect of a low $\left(<2 \mathrm{cmH}_{2} 0\right)$ PEEP strategy with a high PEEP strategy $\left(12 \mathrm{cmH}_{2} \mathrm{O}\right)$ in patients undergoing major abdominal surgery [7]. A set tidal volume of approximately $8 \mathrm{ml} / \mathrm{kg}$ was used in both groups. A high PEEP strategy did not reduce respiratory complications. The authors suggested a lack of efficacy for the prevention of respiratory complications with high PEEP when combined with a low tidal volume strategy. However in this study a low tidal volume of $6 \mathrm{ml} / \mathrm{kg}$ as described in previous trials of protective ventilation in acute lung injury and in previous intraoperative studies was not used [4-6].

\section{Implications for clinical practice}

Given our finding of the frequent intraoperative use of PEEP and its divergence from the standard care group of the above randomized controlled trial by Futier et al. [6], caution is required in the interpretation of such a study and in its widespread application worldwide. It is possible that the absence of PEEP in the standard care group may have been the critical variable. In the randomized multicenter trial by the PROVE Network investigators [7], the study group was consistent with our findings with respect to the use of PEEP. However the amount of PEEP used was either significantly lower or significantly higher than our findings. Currently no significant differences in either postoperative lung function or clinical outcomes have been demonstrated between a high and a low tidal volume strategy in patients undergoing major abdominal surgery where both regimens included the application of PEEP [22]. Thus, we suggest that more studies are needed to understand whether a low tidal volume approach is beneficial even in the presence of PEEP and to assess why, even after exclusion of 
neurosurgery, in close to one fourth of patients, PEEP is not applied.

\section{Strengths and limitations}

Our study is the first to assess current practice of intraoperative ventilation in Australian hospitals. It is prospective and multicenter in nature and included data from a representative sample of over 270 patients from eight teaching hospitals. Whilst our study was performed in a single city, our data included many anesthetists from multiple hospitals and we think it is likely to be representative of national practice in Australia. Treating anaesthetists were blinded to the purpose of the study and only the site investigator and, in some cases, the research coordinator at specific sites were aware of the conduct of the study.

A potential limitation of our study is that it did not exclusively include patients who would be considered at increased risk for postoperative complications. In addition the types of surgery were diverse. However, we wanted to study current practice across all types of patients and a subgroup analysis of patients at increased risk for postoperative acute lung injury found that ventilator practice was the same. We also performed an analysis excluding patients who may have had PEEP or a low tidal volume strategy excluded for other reasons (i.e. intra-cranial neurosurgery). Despite this, the results remained similar. Our study only evaluated ventilator settings at one time point intra-operatively and this observation was assumed to represent the ventilator settings for the duration of the surgery. Potentially ventilator settings may have been altered over the course of the procedure according to clinical need after our data was collected.

\section{Conclusions}

In our cohort of mechanically ventilated patients under general anaesthesia, tidal volume was high and PEEP was applied to the majority of patients but at modest levels. Our findings suggest that, in an Australian cohort, a liberal tidal volume strategy in combination with modest PEEP in selected patients is likely the most common strategy for intra-operative mechanical ventilation and that PEEP application is the dominant standard of care. The findings of our study suggest that the control groups of previous randomized controlled trials do not closely reflect the practice of mechanical ventilation in Australia. In this regard we suggest future clinical research should compare "low tidal volume ventilation with PEEP" to "standard volume ventilation with PEEP". This would allow direct comparison of a low tidal volume ventilator strategy to the current standard of care ventilation practices we observed in this prospective audit of ventilation practices during general anaesthesia in Australian operating rooms.

\section{Abbreviations}

PEEP: Positive end expiratory pressure; $\mathrm{FiO}_{2}$ : Inspired oxygen concentration; ICU: Intensive care unit; ARDS: Acute respiratory distress syndrome; cm: Centimetres; ASA: American Society of Anesthesiologists; AuROC: Area under receiver operator curve; OR: Odds ratio; $\mathrm{Cl}$ : Confidence interval; IQR: Interquartile range; BMI: Body mass index; GA: General anaesthesia; GAETT: General anaesthesia with an endotracheal tube; GAETT high risk: General anaesthesia with an endotracheal tube with increased risk of respiratory complications; ETT: Endotracheal tube; LMA: Laryngeal mask airway; RB: Rigid bronchoscopy; VCV: Volume control ventilation; PCV: Pressure control ventilation; PSV: Pressure support ventilation; SV: Spontaneous ventilation.

\section{Competing interests}

The authors declare that they have no competing interests.

\section{Authors' contributions}

DK: principle author responsible for study design and coordination, data collation, and writing manuscript. LW: Study design, site coordination, collection of data, and writing of manuscript. JG: Data collection, database design and production, revision of manuscript. NG: Statistical analysis and revision of manuscript. GE: Ethics submission editing of manuscript. JD: Study design, Site coordination, data collection, ethics submission, revision of manuscript. RB: Study design, Site coordination, data collection, revision of manuscript. JF: Study design, Site coordination, data collection, revision of manuscript. TP: Study design, Site coordination, data collection, revision of manuscript. LO: Study design, Site coordination, data collection, revision of manuscript. AC: Study design, Site coordination, data collection, revision of manuscript. SW: Site coordination, data collection, revision of manuscript. RB: Study concept and design, writing and revision of manuscript. All authors read and approved the final manuscript.

\section{Acknowledgements}

The authors would like to thank Rochelle Cotter research nurse at the Royal Melbourne Hospital who assisted in the collection of data.

\section{Author details}

${ }^{1}$ Department of Intensive Care, Austin Hospital, Melbourne, Australia. ${ }^{2}$ Department of Anaesthesia, Austin Hospital, Melbourne, Australia. 3 Department of Anesthesia, Royal Melbourne Hospital, Melbourne, Australia. ${ }^{4}$ Department of Anaesthesia, Northern Hospital, Melbourne, Australia. ${ }^{5}$ Department of Anaesthesia, Box Hill Hospital, Melbourne, Australia. ${ }^{6}$ Department of Anaesthesia, Alfred Hospital, Melbourne, Australia. ${ }^{7}$ Department of Anaesthesia, St Vincents Hospital, Melbourne, Australia. ${ }^{8}$ Department of Anaesthesia, Monash Medical Centre, Melbourne, Australia. ${ }^{9}$ Department of Anaesthesia, Western Health, Melbourne, Australia. ${ }^{10}$ University of Melbourne, Melbourne, Australia. ${ }^{11}$ Intensive Care Research, Austin Hospital and Co-director, Australian and New Zealand Intensive Care Research Centre (ANZIC-RC), Melbourne, Australia. ${ }^{12}$ Department of Epidemiology and Preventive Medicine, Monash University, Melbourne, Australia.

Received: 13 May 2014 Accepted: 11 September 2014

Published: 1 October 2014

\section{References}

1. Tenth report of the Victorian consultative council on anaesthetic mortality and morbidity. Epub: http://www.health.vic.gov.au/vccamm/.

2. Wrigge $H$, Pelosi $P$ : Tidal volume in patients with normal lungs during general anaesthesia: lower the better? Anesthesiology 2011, 114:1011-1013.

3. Pinhu L, Whitehead T, Evans T, Griffiths M: Ventilator-associated lung injury. Lancet 2003, 361:332-340,

4. Amato MB, Barbas CS, Medeiros DM, Magaldi RB, Schettino GP, Lorenzi-Filho G, Kairalla RA, Deheinzelin D, Munoz C, Oliveira R, Takagaki TY, Carvalho CR: Effect of a protective-ventilation strategy on mortality in the acute respiratory distress syndrome. N Engl J Med 1998, 338:347-354.

5. Parsons PE, Eisner MD, Thompson BT, Matthay MA, Ancukiewicz M, Bernard GR, Wheeler AP, NHLBI Acute Respiratory Distress Syndrome Clinical Trials Network: Lower tidal volume ventilation and plasma cytokine markers of inflammation in patients with acute lung injury. Crit Care Med 2005, 33:1-6. 
6. Futier E, Constantin JM, Paugam-Burtz C, Futier E, Pascal J, Eurin M, Neuschwander A, Marret E, Beaussier M, Gutton C, Lefrant JY, Allaouchiche B, Verzilli D, Leone M, De Jong A, Bazin JE, Pereira B, Jaber S, IMPROVE Study Group: A trial of intraoperative low-tidal-volume ventilation in abdominal surgery. N Eng J Med 2013, 369:428-437.

7. The PROVE Network Investigators; for the Clinical Trial Network of the European Society of Anaesthesiology: High versus low positive endexpiratory pressure during general anaesthesia for open abdominal surgery (PROVHILO trial): a multicentre randomised controlled trial. Lancet 2014, 384:495-503.

8. Altman DG, Egger M, Pocock SJ, Gøtzsche PC, Vandenbroucke JP, STROBE Initiative: The Strengthening the Reporting of Observational Studies in Epidemiology (STROBE) statement: guidelines for reporting observational studies. Lancet 2007, 370(9596):1453-1457.

9. Pai M, Paloucek FP: The Origin of the "Ideal" Body Weight Equations". Ann Pharmacother 2000, 34:1066-1069.

10. Fernández-Pérez ER, Sprung J, Afessa B, Warner DO, Vachon CM, Schroeder DR Brown DR, Hubmayr RD, Gajic O: Intraoperative ventilator settings and acute lung injury after elective surgery: a nested case control study. Thorax 2009, 64:121-127.

11. Canet J, Gallart L, Gomar C, Paluzie G, Vallès J, Castillo J, Sabaté S, Mazo V, Briones Z, Sanchis J, ARISCAT Group: Prediction of postoperative pulmonary complications in a population-based surgical cohort. Anesthesiology 2010, 113:1338-1350

12. Wanderer JP, Blum, Ehrenfeld JM: Correspondence: intraoperative low-tidal-volume ventilation. N Engl J Med 2013, 369:1861.

13. Levin MA, McCormick PJ, Lin HM, Hosseinian L, Fischer GW: Low intraoperative tidal volume ventilation with minimal PEEP is associated with increased mortality. Br J Anaesth 2014, 113:97-108.

14. Jaber $\mathrm{S}$, Coisel $Y$, Chanques $G$, Futier E, Constantin JM, Michelet $P$, Beaussier M, Lefrant JY, Allaouchiche B, Capdevila X, Marret E: A multicentre observational study of intra-operative ventilatory management during general anaesthesia: tidal volumes and relation to body weight. Anaesthesia 2012, 67:999-1008.

15. Sundar S, Novack V, Jervis K, Bender SP, Lerner A, Panzica P, Mahmood F, Malhotra A, Talmor D: Influence of low tidal volume ventilation on time to extubation in cardiac surgical patients. Anesthesiology 2011, 114:1102-1110.

16. Brower RG, Shanholtz CB, Fessler HE, Shade DM, White P Jr, Wiener CM, Teeter JG, Dodd-o JM, Almog Y, Piantadosi S: Prospective, randomized, controlled clinical trial comparing traditional versus reduced tidal volume ventilation in acute respiratory distress syndrome patients. Crit Care Med 1999, 27:1492-1498.

17. Brochard L, Roudot-Thoraval F, Roupie E, Delclaux C, Chastre J, FernandezMondéjar E, Clémenti E, Mancebo J, Factor P, Matamis D, Ranieri M Blanch L, Rodi G, Mentec H, Dreyfuss D, Ferrer M, Brun-Buisson C, Tobin M, Lemaire F: Tidal volume reduction for prevention of ventilator-induced lung injury in acute respiratory distress syndrome. The Multicenter Trail Group on Tidal Volume reduction in ARDS. Am J Respir Crit Care Med 1998, 158:1831-1838.

18. Stewart TE, Meade MO, Cook DJ, Granton JT, Hodder RV, Lapinsky SE, Mazer CD, McLean RF, Rogovein TS, Schouten BD, Todd TR, Slutsky AS: Evaluation of a ventilation strategy to prevent barotrauma in patients at high risk for acute respiratory distress syndrome. Pressure- and Volume-Limited Ventilation Strategy Group. N Engl J Med 1998, 338:355-361.

19. Ranieri VM, Suter PM, Tortorella C, De Tullio R, Dayer JM, Brienza A, Bruno F, Slutsky AS: Effect of mechanical ventilation on inflammatory mediators in patients with acute respiratory distress syndrome: a randomized controlled trial. JAMA 1999, 282:54-61.

20. Bendixen $\mathrm{HH}$, Hedley-Whyte J, Laver MB: Impaired oxygenation in surgical patients during general anesthesia with controlled ventilation. A concept of atelectasis. N Engl J Med 1963, 269:991-996.

21. Putensen C, Theuerkauf N, Zinserling J, Wrigge H, Pelosi P: Meta-analysis: ventilation strategies and outcomes of the acute respiratory distress syndrome and acute lung injury. Ann Intern Med 2009, 151:566-576.

22. Treschan TA, Kaisers W, Schaefer MS, Bastin B, Schmalz U, Wania V, Eisenberger CF, Saleh A, Weiss M, Schmitz A, Kienbaum P, Sessler DI, Pannen B, Beiderlinden M: Ventilation with low tidal volumes during upper abdominal surgery does not improve postoperative lung function. $\mathrm{Br} J$ Anaesth 2012, 109:263-271.
23. Schultz MJ, Haitsma JJ, Slutsky AS, Gajic O: What tidal volumes should be used in patients without acute lung injury? Anesthesiology 2007, 106:1226-1231.

24. Determann RM, Royakkers A, Wolthuis EK, Vlaar AP, Choi G, Paulus F, Hofstra JJ, de Graaff MJ, Korevaar JC, Schultz MJ: Ventilation with lower tidal volumes as compared with conventional tidal volumes for patients without acute lung injury: a preventive randomized controlled trial. Crit Care 2010, 14(1):R1

25. Michelet P, D'Journo XB, Roch A, Doddoli C, Marin V, Papazian L, Decamps I, Bregeon F, Thomas P, Auffray JP: Protective ventilation influences systemic inflammation after esophagectomy: a randomized controlled study. Anesthesiology 2006, 105:911-919.

26. Choi G, Wolthuis EK, Bresser P, Levi M, van der Poll T, Dzoljic M, Vroom MB, Schultz MJ: Mechanical ventilation with lower tidal volumes and positive end-expiratory pressure prevents alveolar coagulation in patients without lung injury. Anesthesiology 2006, 105:689-695.

27. Severgnini $P$, Selmo G, Lanza C, Chiesa A, Frigerio A, Bacuzzi A, Dionigi G, Novario R, Gregoretti C, de Abreu MG, Schultz MJ, Jaber S, Futier E, Chiaranda M, Pelosi P: Protective mechanical ventilation during general anesthesia for open abdominal surgery improves postoperative pulmonary function. Anesthesiology 2013, 118:1307-1321.

28. Fernández-Pérez ER, Keegan MT, Brown DR, Hubmayr RD, Gajic O: Intraoperative tidal volume as a risk factor for respiratory failure after pneumonectomy. Anesthesiology 2006, 105:14-18.

29. Gajic O, Frutos-Vivar F, Esteban A, Hubmayr RD, Anzueto A: Ventilator settings as a risk factor for acute respiratory distress syndrome in mechanically ventilated patients. Intensive Care Med 2005, 31:922-926.

30. Iscimen R, Cartin-Ceba R, Yilmaz M, Khan H, Hubmayr RD, Afessa B, Gajic O Risk factors for the development of acute lung injury in patients with septic shock: an observational cohort study. Crit Care Med 2008, 36:1518-1522

31. Jia X, Malhotra A, Saeed M, Mark RG, Talmor D: Risk factors for ARDS in patients receiving mechanical ventilation for $>48 \mathrm{~h}$. Chest 2008, 133:853-861.

32. Licker M, Diaper J, Villiger Y, Spiliopoulos A, Licker V, Robert J, Tschopp JM: Impact of intraoperative lung-protective interventions in patients undergoing lung cancer surgery. Crit Care 2009, 13(2):R41.

33. Michelet P, Roch A, Brousse D, D'Journo XB, Bregeon F, Lambert D, Perrin G, Papazian L, Thomas P, Carpentier JP, Auffray JP: Effects of PEEP on oxygenation and respiratory mechanics during one-lung ventilation. Br J Anaesth 2005, 95:267-273.

34. Weingarten TN, Whalen FX, Warner DO, Gajic O, Schears GJ, Snyder MR, Schroeder DR, Sprung J: Comparison of two ventilatory strategies in elderly patients undergoing major abdominal surgery. Br J Anaesth 2010, 104:16-22.

35. Zupancich E, Paparella D, Turani F, Munch C, Rossi A, Massaccesi S, Ranieri VM: Mechanical ventilation affects inflammatory mediators in patients undergoing cardiopulmonary bypass for cardiac surgery: a randomized clinical trial. J Thorac Cardiovasc Surg 2005, 130:378-383.

36. Wrigge $H$, Uhlig $U$, Baumgarten G, Menzenbach J, Zinserling J, Ernst M, Drömann D, Welz A, Uhlig S, Putensen C: Mechanical ventilation strategies and inflammatory responses to cardiac surgery: a prospective randomized clinical trial. Intensive Care Med 2005 31:1379-1387.

37. Reis Miranda D, Gommers D, Struijs A, Dekker R, Mekel J, Feelders R, Lachmann B, Bogers AJ: Ventilation according to the open lung concept attenuates pulmonary inflammatory response in cardiac surgery. Eur J Cardiothorac Surg 2005, 28:889-895

38. Kallet RH, Campbell AR, Dicker RA, Katz JA, Mackersie RC: Effects of tidal volume on work of breathing during lung-protective ventilation in patients with acute lung injury and acute respiratory distress syndrome. Crit Care Med 2006, 34:8-14.

39. van Kaam AH, Lutter R, Lachmann RA, Haitsma JJ, Herting E, Snoek M, De Jaegere A, Kok JH, Lachmann B: Effect of ventilation strategy and surfactant on inflammation in experimental pneumonia. Eur Respir J 2005 26:112-117.

40. van Kaam AH, Lachmann RA, Herting E, De Jaegere A, van Iwaarden F, Noorduyn LA, Kok JH, Haitsma JJ, Lachmann B: Reducing atelectasis attenuates bacterial growth and translocation in experimental pneumonia. Am J Respir Crit Care Med 2004, 169:1046-1053. 
41. Hemmes SN, Serpa Neto A, Schultz MJ: Intraoperative ventilatory strategies to prevent postoperative pulmonary complications: a meta-analysis. Curr Opin Anaesthesiol 2013, 26:126-133.

42. Lau ACW, Lam SM, Yan WW: Benchtop study of leakages across the Portex, TaperGuard and Microcuff endotracheal tubes under simulated clinical conditions. Hong Kong Med J 2013, 20:7-15.

43. Mols G, Priebe HJ, Guttmann J: Alveolar recruitment in acute lung injury. Br J Anaesth 2006, 96:156-166.

doi:10.1186/1471-2253-14-85

Cite this article as: Karalapillai et al:: Current ventilation practice during general anaesthesia: a prospective audit in Melbourne, Australia. BMC Anesthesiology 2014 14:85.

\section{Submit your next manuscript to BioMed Central and take full advantage of:}

- Convenient online submission

- Thorough peer review

- No space constraints or color figure charges

- Immediate publication on acceptance

- Inclusion in PubMed, CAS, Scopus and Google Scholar

- Research which is freely available for redistribution 